OESOPHAGUS

\title{
Relevance of ineffective oesophageal motility during oesophageal acid clearance
}

\author{
M Simrén, J Silny, R Holloway, J Tack, J Janssens, D Sifrim
}

Gut 2003;52:784-790

\begin{abstract}
Background: Oesophageal clearance of acid reflux consists of an initial volume clearance followed by neutralisation of the acidified mucosa by swallowed saliva (chemical clearance). Ineffective oesophageal motility (IOM), a frequent finding in patients with gastro-oesophageal reflux disease (GORD), has been claimed to underlie prolonged acid clearance by affecting oesophageal emptying and saliva transport. Intraluminal impedance allows non-radiological monitoring of movement of oesophageal liquids.

Aims: To evaluate the relevance of IOM during oesophageal volume and chemical clearance using combined $\mathrm{pH}$ impedance measurements.

Subjects: Impedance was validated with fluoroscopy to study volume clearance in three healthy subjects. Acid clearance tests were performed in 10 healthy subjects in the upright and supine positions, before and after oesophageal peristaltic disruption with sildenafil $50 \mathrm{mg}$ Methods: After instillation of an acid bolus, simultaneous manometry, $\mathrm{pH}$, and impedance were used to study oesophageal motility, chemical clearance, and volume clearance, respectively. Results: Impedance allowed assessment of volume clearance accurately, showing a strong correlation with fluoroscopy $\left(r^{2}=0.89\right)$. Sildenafil provoked a graded impairment in oesophageal motility in healthy subjects without affecting saliva secretion. In the upright position, volume clearance was slightly prolonged only with severe $\mathrm{IOM}$ (>80\% abnormal peristaltic sequences). In the supine position, severe IOM significantly prolonged chemical and volume clearance. Moderate IOM (30-80\% abnormal peristalsis) had no effect. With normal peristalsis and moderate IOM, clearance times were similar in the upright and supine positions. Severe IOM however had a greater impact on clearance in the supine than in the upright position.

Conclusion: Ineffective oesophageal motility has little effect on oesophageal clearance during upright acid reflux. With supine reflux, only severe IOM is associated with prolonged oesophageal clearance.
\end{abstract}

See end of article for authors' affiliations

Correspondence to: Dr D Sifrim, Faculty of Medicine KU Leuven, Lab G-I Physiopathology, O\&N Gasthuisberg, 7th floor, Herestraat 49, 3000, Leuven, Belgium Daniel.Sifrim@

med.kuleuven.ac.be

Accepted for publication 12 December 2002

G stro-oesophageal reflux disease (GORD) is characterised by increased exposure of the oesophageal mucosa to gastric contents. This is mainly due to a variable combination of an increased number of gastro-oesophageal reflux episodes and abnormally prolonged clearance of the refluxed material. ${ }^{1-3}$ Oesophageal clearance function has been studied using pH metry, scintigraphy, manometry, and videofluoroscopy either separately or in combination. ${ }^{4-10}$ These studies have demonstrated that oesophageal acid clearance consists of two processes: firstly, rapid removal of most of the intraluminal refluxate, achieved by gravity and primary or secondary peristalsis (volume clearance), followed by a slow neutralisation of the acidified mucosa by swallowed saliva (chemical clearance).

Prolonged $\mathrm{pH}$ monitoring has suggested that many patients with GORD have impaired oesophageal acid clearance. ${ }^{23}$ However, these studies could not determine whether the abnormality in those patients was due to impaired volume clearance, insufficient acid neutralisation, or both. The relative importance of gravity and efficient peristalsis for oesophageal clearance remains controversial. Whereas clearance of spontaneous acid reflux episodes has been assessed both in the upright and supine positions during ambulatory $\mathrm{pH}$ metry studies, ${ }^{4}$ the volume clearance function has mostly been studied with subjects in the supine position during stationary videofluoroscopic or scintigraphic examinations after instillation of barium or a radioactive bolus in the distal oesophagus. ${ }^{6} 7910$

Intraluminal electrical impedance has been introduced recently as a technique to investigate the characteristics of bolus transport in the oesophagus and duodenum. ${ }^{11}{ }^{12}$ This technique is based on changes in electrical impedance between two electrodes during passage of a bolus, and permits assessment of liquid movement within the oesophageal lumen. ${ }^{13}$ Both swallowed and refluxed liquids lead to a drop in impedance that returns to baseline values after emptying of the oesophageal lumen. ${ }^{14}$ Impedance has been proposed as a non- radiological tool for studying oesophageal volume clearance after reflux ${ }^{15}$ but specific validation studies are not available.

The term ineffective oesophageal motility (IOM) has been coined recently to describe the pattern of peristaltic failure observed during manometric studies in patients with nonspecific motor disorders or atypical GORD symptoms, ${ }^{16} 17$ although a number of oesophageal body motor abnormalities have been described previously in patients with GORD. ${ }^{18}$ Coexistence of abnormal motility, prolonged oesophageal emptying, and delayed acid clearance strongly suggested a direct causal relationship. ${ }^{18}$ However, clearance is highly affected by body position. Patients with systemic sclerosis in the upright position may have normal or even accelerated clearance even in the absence of oesophageal body motility. ${ }^{19}$

Compared with normal subjects, patients with IOM have prolonged supine clearance times. ${ }^{16}$ A causal relationship between IOM and delayed clearance could be examined by

Abbreviations: IOM, ineffective oesophageal motility; GORD, gastro-oesophageal reflux disease; cGMP, cyclic guanosine monophosphate; LOS, lower oesophageal sphincter. 

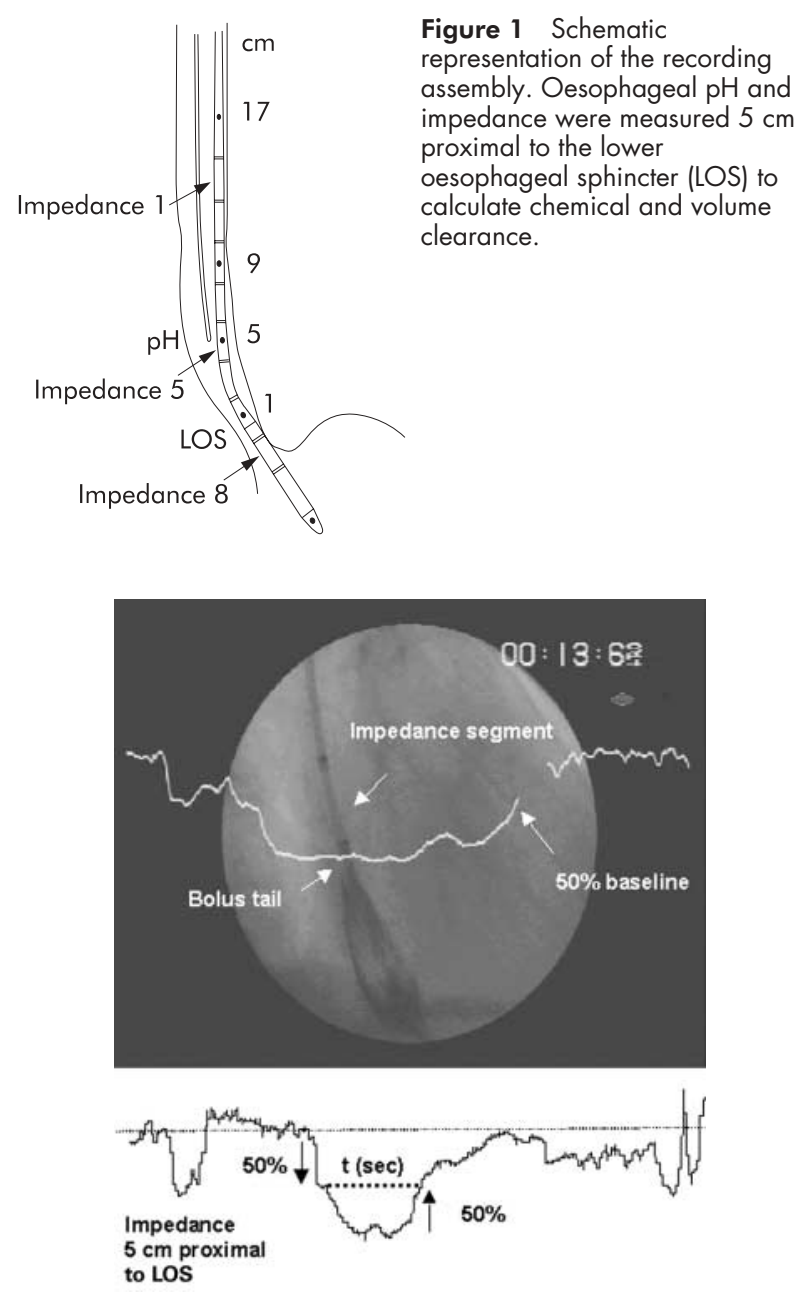

Figure 2 Validation of oesophageal impedance for assessment of volume clearance. Fluoroscopic imaging and oesophageal impedance were recorded concurrently during barium swallows. An impedance segment was positioned $5 \mathrm{~cm}$ proximal to the lower oesophageal sphincter (LOS). During barium swallows fluoroscopic imaging, impedance recording, and a digital timer were simultaneously displayed on a single screen. The following parameters were compared: (a) time to complete filling with barium of the oesophageal segment; (b) time to complete disappearance of barium from the oesophageal segment; (c) time to $50 \%$ drop in impedance relative to the pre-swallow baseline; and (d) time to return of impedance to $50 \%$ of baseline

comparing oesophageal clearance before and after impairment of oesophageal peristalsis in the same subject. This has been attempted using anticholinergic agents ${ }^{69}$ but their effect on saliva production prevented separate assessment of the effect of impaired motility on oesophageal clearance.

Nitric oxide regulates the amplitude and progression of oesophageal peristaltic contractions..$^{20}$ The effect of nitric oxide is mediated by an increase in intracellular cyclic guanosine monophosphate (cGMP). Sildenafil, a drug used to improve functional impotence, ${ }^{21}$ increases cGMP and has a profound effect on oesophageal motility. ${ }^{22}$ In healthy subjects, sildenafil provokes a gradual and reversible reduction in the amplitude of peristaltic contractions that even disappear approximately 10-15 minutes after administration..$^{24}$ Theoretically, an increase in cGMP by sildenafil would not significantly affect saliva secretion. ${ }^{25}$

We hypothesised that pharmacologically induced progressive oesophageal dysmotility would provoke prolonged volume clearance and impaired saliva transport. The aims of this study were: (1) to evaluate the effect of IOM induced by sildenafil on volume and chemical clearance and (2) to validate
Table 1 Validation of oesophageal impedance for assessment of volume clearance

\begin{tabular}{lll}
\hline $\begin{array}{l}\text { Time from swallow to: } \\
(\mathrm{n}=35)\end{array}$ & $\begin{array}{l}\text { Videofluoroscopy } \\
\text { (seconds) }\end{array}$ & $\begin{array}{l}\text { Impedance } \\
\text { (seconds) }\end{array}$ \\
\hline Oesophageal filling & $2.14(0.18)$ & $2.01(0.11)$ \\
Oesophageal emptying & $5.93(0.50)$ & $5.56(0.32)$ \\
Interval filling-emptying & $3.79(0.39)$ & $3.55(0.33)$ \\
$\quad$ (volume clearance time) & & \\
\hline
\end{tabular}

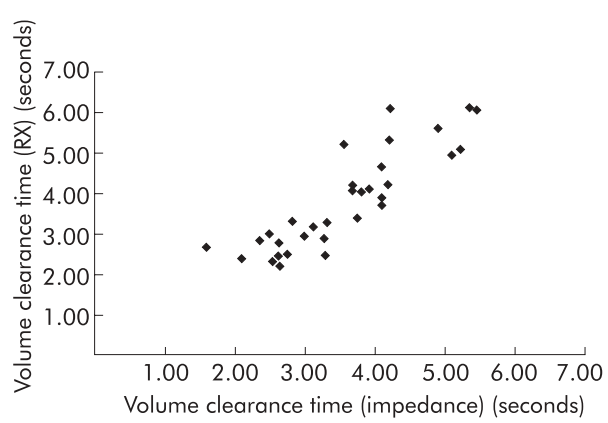

Figure 3 Scattergram describing the relationship between volume clearance time of a swallowed barium bolus as measured by videofluoroscopy and oesophageal intraluminal impedance.

intraluminal electrical impedance as a technique to assess oesophageal volume clearance.

\section{METHODS}

\section{Subjects}

Studies were performed in 13 healthy subjects (eight men; median age 41 years (range 18-61)). All subjects were free of gastrointestinal symptoms and had no evidence of acute or chronic illness. None of the subjects was taking medications known to influence oesophageal motor function. Written informed consent was obtained from each participant before the study. The ethics committee of the University Hospital had previously approved the protocol.

\section{Oesophageal manometry and $\mathrm{pH}$}

Oesophageal manometry was performed with a perfused multilumen manometric assembly (DentSleeve Pty Ltd, Wayville, Australia). A $6 \mathrm{~cm}$ long sleeve sensor recorded lower oesophageal sphincter (LOS) pressure. A sidehole at the distal margin of the sleeve recorded gastric pressure, and the oesophageal body pressure was recorded at 1, 5, 9, and $17 \mathrm{~cm}$ proximal to the LOS (fig 1). A side hole in the pharynx monitored swallows. Each lumen was perfused with distilled water at $0.5 \mathrm{ml} / \mathrm{min}$ using a pneumohydraulic capillary perfusion pump (Arndorfer Medical Specialties Inc., Greendale, Wisconsin, USA). Pressures were sensed by external pressure transducers (pvb; Medizintechnik, Munich, Germany). Oesophageal $\mathrm{pH}$ was measured with an antimony $\mathrm{pH}$ electrode (Synectics Medical, Stockholm, Sweden) positioned $5 \mathrm{~cm}$ proximal to the LOS. The $\mathrm{pH}$ electrode was calibrated in buffer solutions of $\mathrm{pH} 1$ and 7 before each study. Pressure and pH signals were amplified using a modified Synectics PC Polygraf 16HR (Synectics Medical), and the corresponding analogue outputs were digitised together with the impedance measurement output and stored on computer for subsequent analysis.

\section{Oesophageal impedance}

Oesophageal impedance was recorded continuously with a series of cylindrical electrodes, each $2 \mathrm{~mm}$ in axial length, spaced at $2 \mathrm{~cm}$ intervals, and incorporated into the manometric assembly (DentSleeve Pty Ltd). Each pair of electrodes formed a 
Table 2 Effects of sildenafil on volume and buffering capacity of saliva

\begin{tabular}{lccc}
\hline & & \multicolumn{3}{l}{ After clearance tests } \\
\cline { 3 - 4 } Saliva & Basal & Pre-sildenafil & Post-sildenafil \\
\hline Volume (ml/15 minutes) & $13.8(9.5)$ & $15.2(8.5)$ & $13.2(6.3)$ \\
$\mathrm{pH}$ & $6.83(0.38)$ & $6.87(0.47)$ & $6.83(0.43)$ \\
Buffering capacity (ml HCl 0.1 N) & $0.72(0.28)$ & $0.68(0.29)$ & $0.67(0.27)$ \\
\hline
\end{tabular}

Upright

Basal

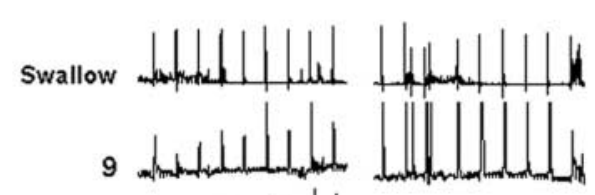

Manometry

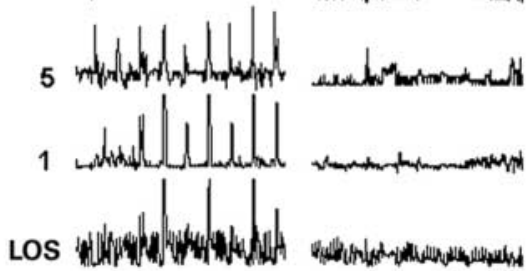

pH

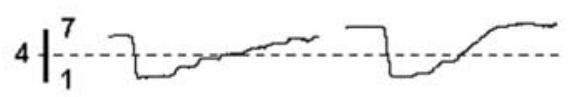

Impedance

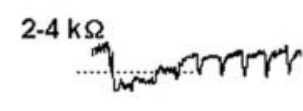

Acid bolus $\hat{\uparrow}$

Sildenafil

\section{4}

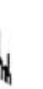

(1)

\section{(I)}

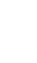
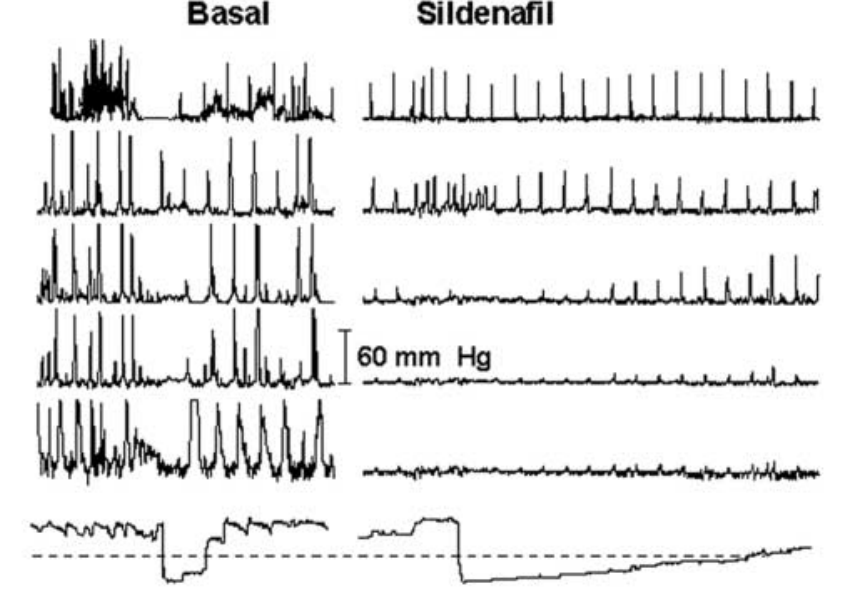

Supine 

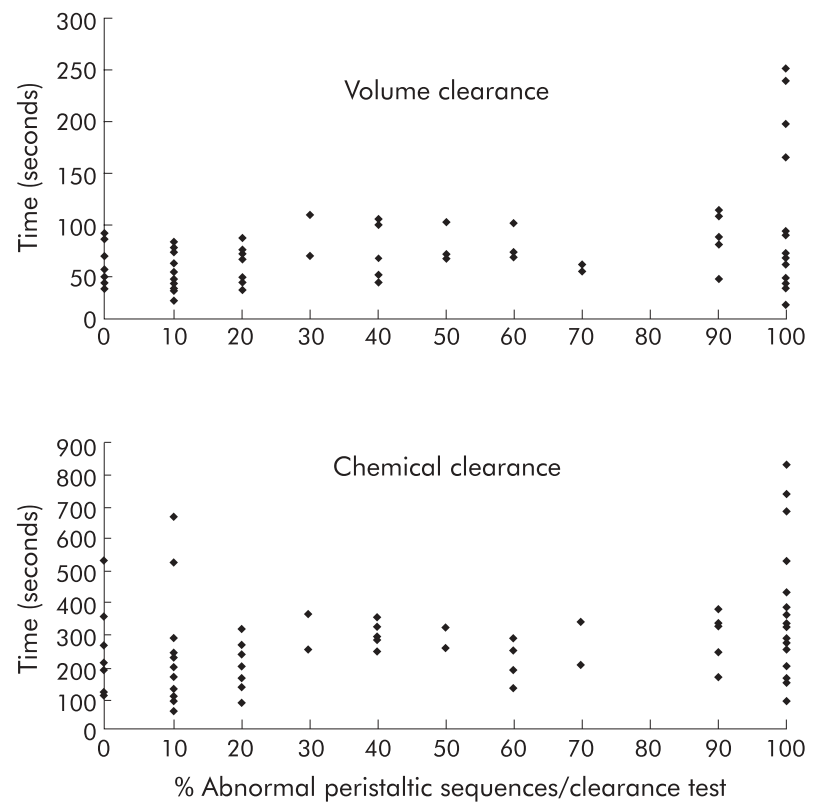

Figure 5 Correlation between the proportion of abnormal peristaltic sequences and clearance times in the upright position (pooled data).

$10 \mathrm{ml}$ of water was administered through the central channel of the manometric catheter into the stomach and the clearance test was performed another four times starting two minutes after drug administration.

\section{Data analysis}

Validation of oesophageal impedance for assessment of volume clearance

Video images from the barium swallows were digitised at 4 frames/s. Dedicated software (E Bellon, KU Leuven, Belgium) allowed the display of the images frame by frame, thereby ensuring direct comparison of fluoroscopic and impedance tracking of the bolus movement at any particular point in time. After each swallow, the timing of barium movement (on fluoroscopy) and impedance changes were analysed separately. The following parameters were measured: (a) time from swallow to complete filling with barium of the oesophageal segment between 6 and $4 \mathrm{~cm}$ proximal to the LOS; (b) time from swallow to complete disappearance of barium from the segment between 6 and $4 \mathrm{~cm}$ proximal to the LOS; (c) time from swallow to $50 \%$ drop in impedance relative to the pre-swallow baseline; and (d) time from swallow to return of impedance to $50 \%$ of baseline (fig 2). The impedance change to $50 \%$ of baseline values was selected based on preliminary studies by Silny and colleagues. ${ }^{11}$

\section{Clearance studies}

$\mathrm{pH}$, impedance, and manometric signals were digitised together and displayed on a single computer screen for analysis, using a dedicated software program (Review, A Andrioli, KU Leuven, Belgium). After infusion of the $15 \mathrm{ml}$ acid bolus, oesophageal chemical clearance time was calculated from the $\mathrm{pH}$ trace according to Helm and colleagues, ${ }^{5}$ and volume clearance time was calculated from the impedance recording based on our previous validation study. Both oesophageal chemical and volume clearance were measured $5 \mathrm{~cm}$ proximal to the LOS. Oesophageal chemical clearance time was defined as the time in seconds from instillation of the acid until oesophageal $\mathrm{pH}$ recovered to a value of 4 . Oesophageal volume clearance time was defined as the time in seconds from the acid instillation induced drop in impedance to below $50 \%$ of baseline until impedance recovered to above $50 \%$ of baseline.

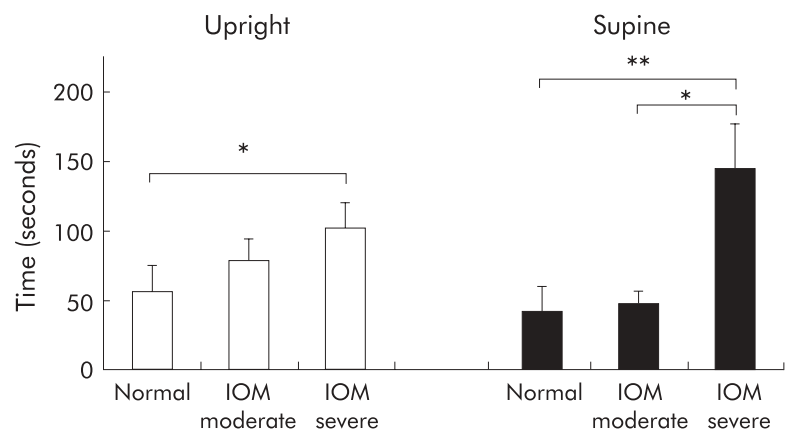

Figure 6 Volume clearance in the upright and supine positions with increasing severity of ineffective oesophageal motility (IOM) in seven subjects who all had three levels of impairment of oesophageal motility. ${ }^{*} p<0.05,{ }^{*} p<0.01$.

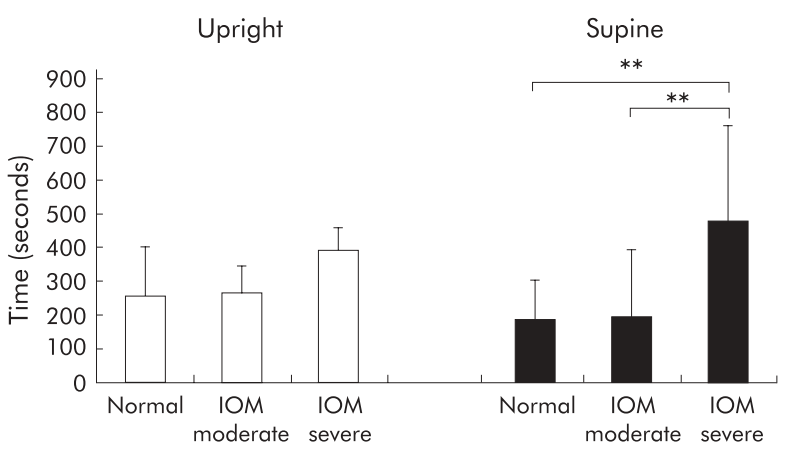

Figure 7 Chemical clearance in the upright and supine positions with increasing severity of ineffective oesophageal motility (IOM) in seven subjects who all had three levels of impairment of oesophageal motility. ${ }^{* *} p<0.01$.

The manometric characteristics of the first 10 peristaltic sequences after acid instillation were assessed during each clearance test. A peristaltic sequence was considered to be abnormal if the amplitude of contractions in the distal oesophageal body ( 5 and/or $9 \mathrm{~cm}$ proximal to the LOS) was $<30 \mathrm{~mm} \mathrm{Hg}$ or if the contractions were simultaneous. IOM was defined according to Leite and colleagues ${ }^{16} 17$ and was considered to be present if $30 \%$ or more of the peristaltic sequences were abnormal. The level of impairment of peristalsis was further classified as: (a) normal peristalsis ( $<30 \%$ of peristaltic sequences abnormal); (b) moderate IOM (30-80\% of peristaltic sequences abnormal); and (c) severe IOM ( $>80 \%$ of peristaltic sequences abnormal).

The relationship between abnormal oesophageal peristalsis and clearance was analysed in two ways. Firstly, by pooling all clearance tests in all subjects, we calculated the overall correlation between the proportion of abnormal peristaltic sequences and clearance times. Secondly, for those subjects in whom we could analyse at least one clearance test in each level of abnormal peristalsis, we compared the clearance times at the three different levels of impairment of oesophageal motility - that is, normal peristalsis versus moderate and severe IOM. Only those subjects who had all three different levels of impairment of oesophageal motility were included in this analysis.

The impact of body position on the effect of IOM on oesophageal clearance was also assessed. We first calculated the relative change in clearance time $\left(\mathrm{RC}_{\text {clearance }}\right)$ induced by IOM as follows:

$$
\mathrm{RC}_{\text {clearance }}=\left(\text { clearance }_{\text {IOM }}-\text { clearance }_{\text {NORMAl }}\right) / \text { clearance }_{\text {NORMAL }} .
$$

Thereafter, $\mathrm{RC}_{\text {clearance }}$ in the upright and supine positions was compared in each subject. 
Clearance tests in which spontaneous gastro-oesophageal reflux was detected by $\mathrm{pH}$ and/or impedance during the $\mathrm{pH}$ recovery period were excluded from the analysis.

\section{Statistical analysis}

Data are presented as mean (SD) unless otherwise stated. Pearson's linear correlation was used for correlation analyses. The paired Student's $t$ test or repeated measures ANOVA followed by a post hoc analysis using the Bonferroni correction were used for comparison of clearance tests between the three different levels of impaired oesophageal motility. Statistical significance was accepted when $\mathrm{p}<0.05$.

\section{RESULTS}

\section{Validation of oesophageal impedance for assessment} of volume clearance

A total of 35 swallows (13 (7-15) per subject) were analysed from the three healthy volunteers. Volume clearance of the swallowed barium was determined to be almost identical by videofluoroscopy and impedance (table 1, fig 3). There was a strong correlation between both methods for measurement of the time to oesophageal filling $\left(r^{2}=0.89 ; \mathrm{p}<0.0001\right)$ as well as the time to oesophageal emptying $\left(r^{2}=0.79 ; \mathrm{p}<0.0001\right)$.

\section{Effects of sildenafil on volume and buffering capacity of saliva}

Compared with the basal period (after intubation), repetitive intraoesophageal acid instillation during the clearance tests did not modify the volume and characteristics of saliva.

Sildenafil neither reduced the volume of saliva $(\mathrm{ml} / 15 \mathrm{~min}$ utes) nor modified the $\mathrm{pH}$ or buffering capacity of saliva (table 2).

\section{Effects of sildenafil on lower oesophageal sphincter pressure}

Sildenafil significantly reduced LOS basal tone without affecting dry swallow induced residual pressures. In the supine position, LOS pressure was 15.6 (6) $\mathrm{mm} \mathrm{Hg}$ before and 6.4 (5) $\mathrm{mm} \mathrm{Hg}$ between 15 and 20 minutes after sildenafil administration $(\mathrm{p}<0.05)$.

\section{Clearance tests}

Intraoesophageal acid instillation was followed by a short lasting volume clearance, detected as recovery of oesophageal impedance, and a longer lasting chemical clearance, detected as a stepwise recovery of oesophageal $\mathrm{pH}$. Under basal conditions, both in the upright and supine positions, clearance tests were followed by swallow induced normal peristaltic waves (fig 4).

Sildenafil gradually decreased peristaltic wave amplitude and disrupted propagation such that peristalsis became ineffective. The time between sildenafil administration and the start of oesophageal dysmotility varied between 2 and 10 minutes. After sildenafil, we analysed 12 clearance tests with normal motility ( $<30 \%$ abnormal peristalsis), 21 clearance tests with moderate IOM (30-80\% abnormal peristalsis), and 42 clearance tests with severe IOM ( $>80 \%$ abnormal peristalsis). Five clearance tests before and five after sildenafil were excluded due to spontaneous gastro-oesophageal reflux during the recovery period. Sildenafil was generally well tolerated. One subject had severe headache and three subjects experienced facial flushing.

\section{Relationships between abnormal oesophageal} peristalsis, body position, and oesophageal clearance In the upright position only a weak correlation existed between the proportion of abnormal peristaltic sequences and both volume and chemical clearance times $\left(r^{2}=0.14 ; \mathrm{p}=0.002\right)$ and $\left(r^{2}=0.12 ; \mathrm{p}=0.003\right)$ respectively. Prolonged volume and chemical clearance times were infrequent and mainly
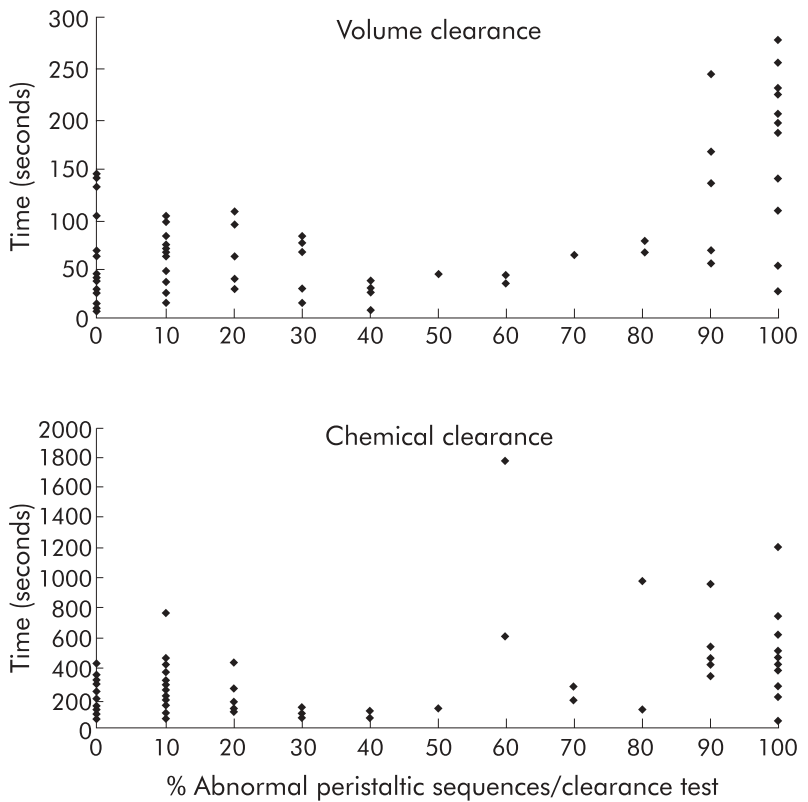

Figure 8 Correlation between the proportion of abnormal peristaltic sequences and clearance times in the supine position (pooled data).

observed during clearance tests with the highest proportion of abnormal peristalsis (fig 5). Volume clearance was slightly prolonged only with severe IOM $(p<0.05)$ (fig 6). Chemical clearance however was not significantly affected in the upright position (fig 7). The correlation between volume and chemical clearance times in the upright position was weak $\left(r^{2}=0.24 ; \mathrm{p}<0.0001\right)$.

In the supine position, the correlation between the proportion of abnormal peristaltic sequences and clearance times was weak but tended to be stronger than that in the upright position $\left(r^{2}=0.21 ; \mathrm{p}<0.0001\right.$ and $\left.r^{2}=0.36 ; \mathrm{p}<0.0001\right)$ (fig 8). Prolonged volume clearance time was obvious only during clearance tests with severe IOM. With severe IOM, both volume and chemical clearance times were significantly prolonged $(p=0.001)$ but there were no differences in clearance times between tests with normal peristalsis and moderate IOM (figs 5,6). The correlation between volume and chemical clearance times was weak $\left(r^{2}=0.32 ; \mathrm{p}<0.0001\right)$ but tended to be stronger in the supine than in the upright position.

IOM affected oesophageal clearance slightly in the upright position and markedly in the supine position. This was only true with severe IOM. The relative change in clearance times induced by moderate IOM was similar in the upright and supine positions. In contrast, with severe IOM the relative change in both volume $(2.7(2.2) v 0.75(1.2) ; \mathrm{p}<0.05)$ and chemical clearance $(3.5(3.7) v 1.04(0.9) ; \mathrm{p}=0.09)$ was higher in the supine than in the upright position.

\section{DISCUSSION}

Oesophageal peristalsis is generally believed to be an important factor in the clearance of acid from the oesophagus, and that impaired oesophageal peristalsis is a major reason for prolongation of oesophageal acid exposure in reflux disease. However, these concepts have been based on extrapolations from results of radiological or radionuclide measurement of volume clearance, predominantly in supine subjects. In this study we have assessed the impact of IOM and gravity during oesophageal acid clearance by direct and concurrent measurement of volume and chemical clearance using intraluminal electrical impedance and $\mathrm{pH}$ monitoring. Our study has shown that moderate degrees of IOM produced by sildenafil 
have little impact on volume or chemical oesophageal clearance. Only severely ineffective peristalsis, with $>80 \%$ of abnormal peristaltic sequences, significantly impairs clearance, particularly in the supine position.

Understanding the mechanisms of impaired acid clearance requires measurement of both volume and chemical clearance. Most previous studies have used only oesophageal $\mathrm{pH}$ monitoring which does not differentiate between the two. Simultaneous assessment of oesophageal motility, volume clearance, and chemical clearance has been performed previously. ${ }^{70}{ }^{27-29}$ However, the number of volume clearance events that were analysed in these studies was limited by the use of radiation. Our study incorporated two novel methodological approaches: the use of intraluminal electrical impedance to measure volume clearance, and administration of sildenafil to cause a graded impairment in oesophageal motility. Intraluminal electrical impedance has been introduced recently as a technique to investigate bolus transport in the oesophagus and duodenum. ${ }^{11-13}$ We have validated the impedance technique to study oesophageal volume clearance by tracking the movement of a swallowed barium bolus with simultaneous fluoroscopy and impedance. A strong correlation was found between the two methods and thus impedance was able to determine accurately the timing of oesophageal lumen filling and emptying. Furthermore, the lack of radiation hazards permitted monitoring of multiple clearance tests in each subject and thereby evaluation of the impact of varying severities of peristaltic impairment on oesophageal clearance.

Previous studies used anticholinergic agents such as propantheline or atropine to assess the role of oesophagea motility during clearance. ${ }^{69}{ }^{10}$ However, these drugs reduce saliva secretion and are therefore not suitable to assess the relative roles of oesophageal motility and saliva in oesophageal clearance function. We used sildenafil, a drug known to affect oesophageal motility. ${ }^{21-24}$ Sildenafil had no effect on salivary volume, $\mathrm{pH}$, or buffering capacity suggesting that cGMP has no significant role in human saliva secretion. Sildenafil provoked a gradual reduction in the amplitude of swallow induced peristaltic contractions up to their complete abolition approximately 15 minutes after administration, thereby allowing us to assess the impact of progressive degrees of peristaltic failure during the subsequent clearance tests. As expected, sildenafil also decreased LOS pressure. ${ }^{22}{ }^{24}$ This effect neither accelerated oesophageal clearance in the upright position nor increased the number of spontaneous acid reflux events in the recovery period during the clearance tests. Therefore, the effect of sildenafil on oesophageal clearance could only be attributed to abnormal motility in the oesophageal body.

Patients with GORD frequently exhibit abnormal oesophageal peristalsis. ${ }^{18}$ The term IOM, characterised by an increased proportion of low amplitude pressure waves, has been coined recently to designate the most common pattern of peristaltic failure found in patients with reflux disease. ${ }^{16} 17$ Our data however do not support the notion that IOM is of major importance in the delayed clearance of acid reflux. In the upright position, IOM had only modest impact on volume clearance and no significant effect on acid clearance, and in the supine posture only severe IOM prolonged oesophageal clearance. We did not find a linear correlation in our clearance tests between per cent peristaltic failure and clearance times. For example, clearance tests with $30 \%$ and $75 \%$ peristaltic failure showed similar clearance times whereas only those with more than $80 \%$ failure showed a clear prolonged clearance. Moreover, a separate analysis of the effect of normal peristalsis and moderate IOM ( $30-80 \%$ of abnormal peristaltic sequences) on oesophageal acid clearance in each subject failed to reveal any significant differences. Oesophageal clearance in patients with GORD may be affected by motility disturbances either in the stomach, LOS, oesophageal body, or pharynx. In the current study we only evaluated the effect of sildenafil in the oesophageal body and LOS pressure. IOM induced by sildenafil matches the pattern described in patients with GORD but further studies are needed to evaluate the effect of sildenafil on other factors potentially involved in abnormal oesophageal clearance in these patients-that is, proximal gastric motility, oesophageal tone, or triggering of secondary peristalsis.

It has been suggested that normal peristalsis not only plays a major role in volume clearance of acid reflux but is also required for transport of saliva to the distal oesophagus. We hypothesised that disruption of oesophageal peristalsis would affect significantly distal acid neutralisation by affecting saliva transport. In the upright position however impairment of peristalsis in the smooth muscle oesophagus by sildenafil had no significant effect on chemical clearance, suggesting that saliva can reach the distal oesophagus if moved by an effective pharyngeal pump and gravity.

There are a number of potential explanations for the failure of IOM to impair acid clearance. Firstly, the definition of IOM may not be entirely appropriate. It is based on the concept that pressure waves in the distal oesophagus lower than $30 \mathrm{~mm} \mathrm{Hg}$ in amplitude are associated with failure of bolus clearance measured either radiologically ${ }^{7}$ or scintigraphically. ${ }^{10}$ However, careful inspection of the data reveals that the rate of failed clearance with waves with amplitudes of 21-30 mm Hg was only $56 \%$ and it was not until wave amplitudes fell below $21 \mathrm{~mm} \mathrm{Hg}$ that consistent clearance failure occurred. ${ }^{7}$ Thus ineffective motility associated with pressure waves $>21 \mathrm{~mm}$ $\mathrm{Hg}$ might not be expected to impair volume clearance. In the present study, sildenafil usually caused almost complete abolition of pressure waves. Thus issues of definition of IOM are unlikely to be the only explanation.

Secondly, gravity may be a major factor. Previous studies have shown that gravity contributes little to oesophageal acid clearance in the presence of normal peristalsis ${ }^{8}$ but it is important in patients with severe oesophageal dysmotility such as with scleroderma. ${ }^{19}$ In those studies volume clearance was not assessed. To the best of our knowledge, studies to date assessing oesophageal volume clearance have been performed in the supine position. Our study showed that with normal peristalsis body position has no effect on chemical and volume clearance. Also, in the presence of moderate IOM there is no difference between clearance times in the upright and supine positions. However, when ineffective motility is severe, oesophageal clearance is significantly longer in the supine than in the upright position.

In patients with non-erosive and mild to moderate erosive reflux disease, most acid reflux events occur in the upright position during the day. In this population, acid clearance may be prolonged in spite of normal oesophageal peristalsis. ${ }^{30}$ Previous studies have shown that only $14 \%$ of patients with nonerosive reflux disease and $25 \%$ of patients with mild oesophagitis may have more than $51 \%$ peristaltic failure. ${ }^{18}$ Supine and bipositional gastro-oesophageal reflux occur in patients with more severe GORD. ${ }^{31}$ These patients have a higher prevalence of abnormal primary peristalsis. ${ }^{18}$ Unlike other studies in supine GORD patients ${ }^{29}$ in our study moderate IOM failed to prolong oesophageal clearance. Our data therefore do not support the notion that moderate IOM (less than $80 \%$ of peristaltic failure) is of major importance in the delayed clearance of acid reflux in the upright position.

Factors other than motor dysfunction of the distal oesophagus may be of greater importance for the prolonged oesophageal acid clearance observed in patients with upright reflux. The interval between reflux and the first peristaltic sequence and the frequency of swallows after reflux might affect clearance in these patients. ${ }^{32}$ Reflux that occurs when oesophageal $\mathrm{pH}$ is below 4 , the so-called re-reflux, can artefactually prolong clearance time by combining separate reflux episodes. Although this phenomenon occurs predominantly in the 
supine position, it can also explain prolonged reflux events in the upright position, particularly in patients with non-erosive reflux disease. ${ }^{33}$ Patients with hiatal hernia may have delayed oesophageal clearance due to repeated re-reflux episodes and/or abnormal emptying of the very distal oesophagus as a consequence of impaired swallow induced oesophageal shortening and re-lengthening. ${ }^{34}$ The contribution of IOM to delayed clearance in patients with hiatal hernia requires further investigations. Lastly, it is possible that preservation of normal swallowing, pharyngeal pump, and proximal oesophageal motility, not affected by sildenafil, could have helped oesophageal clearance in the healthy subjects.

In summary, we have analysed the role of different degrees of oesophageal dysmotility during oesophageal clearance. Our results suggest that IOM of moderate degree has little impact in oesophageal clearance during upright reflux. Only severe IOM is associated with prolonged oesophageal clearance in the supine position. Even if oesophageal dysmotility is commonly found during manometric studies in patients with GORD, ${ }^{35}$ the majority of these patients do not have severe IOM, according to the definitions used in our study. In clinical terms, our results do not support the pharmacological treatment of mild oesophageal dysmotility in patients with GORD but encourages the development of prokinetic agents able to convert severe IOM into moderate IOM with its lower impact on oesophageal clearance.

\section{ACKNOWLEDGEMENT}

This work was supported by grants from the FWO and the "Geconcerteerde Onderzoeksactie" of the University of Leuven.

\section{Authors' affiliations}

\section{Simrén*, J Tack, J Janssens, D Sifrim, Centre for}

Gastroenterological Research, Catholic University of Leuven, Belgium J Silny, Research Centre for Bioelectromagnetic Interaction, FEMU, University Hospital Aachen, Germany

R Holloway, Department of Gastroenterology, Hepatology, and General Medicine, Royal Adelaide Hospital, South Australia, Australia

*Present address: Section of Gastroenterology, Department of Internal Medicine, Sahlgrenska University Hospital, S-41345 Gothenburg, Sweden

\section{REFERENCES}

1 Dodds WJ, Dent J, Hogan WJ, et al. Mechanisms of gastroesophageal reflux in patients with reflux esophagitis. $N$ Engl J Med 1982;307: 1547-52

2 Richter J. Do we know the cause of reflux disease? Eur J Gastroenterol Hepatol 1999;11(suppl 1):S3-9.

3 Orlando RC. Overview of the mechanisms of gastroesophageal reflux. Am J Med 2001;111(suppl 8A):174-7S.

4 Barham CP, Gotley DC, Miller R, et al. Pressure events surrounding oesophageal acid reflux episodes and acid clearance in ambulant healthy volunteers. Gut 1993;34:444-9.

5 Helm JF, Dodds WJ, Riedel DR, et al. Determinants of esophageal acid clearance in normal subjects. Gastroenterology 1983;85:607-12.

6 Helm JF, Dodds WJ, Pelc LR, et al. Effect of esophageal emptying and saliva on clearance of acid from the esophagus. N Engl J Med 1984;310:284-8

7 Kahrilas PJ, Dodds WJ, Hogan WJ. Effect of peristaltic dysfunction on esophageal volume clearance. Gastroenterology 1988;94:73-80.
8 Kjellen G, Tibbling L. Influence of body position, dry and water swallows, smoking, and alcohol on esophageal acid clearing. Scand J Gastroenterol 1978.13.283-8.

9 Phaosawasdi K, Malmud LS, Tolin RD, et al. Cholinergic effects on Phaosawasdi K, Malmud LS, Tolin RD, et al. Cholinergic effects on
esophageal transit and clearance. Gastroenterology 1981;81:915-20.

10 Richter JE, Blackwell JN, Wu WC, et al. Relationship of radionuclide liquid bolus transport and esophageal manometry. J Lab Clin Med 1987; 109:217-24.

11 Silny J. Intraluminal multiple electrical impedance procedure for measurement of gastrointestinal motility. J Gastrointest Motil 1991; 3:151-62.

12 Nguyen HN, Silny J, Wuller S, et al. Chyme transport patterns in human duodenum, determined by multiple intraluminal impedancometry. Am J Physiol 1995;268:G700-8.

13 Silny J, Knigge KP, Fass J, et al. Verification of the intraluminal multiple electrical impedance measurement for the recording of gastrointestinal motility. J Gastrointest Motil 1993;5: 107-22.

14 Sifrim D, Silny J, Holloway RH, et al. Patterns of gas and liquid reflux during transient lower oesophageal sphincter relaxation: a study using intraluminal electrical impedance. Gut 1999:44:47-54

15 Skopnik H, Silny J, Heiber O, et al. Gastroesophageal reflux in infants: evaluation of a new intraluminal impedance technique. J Pediatr Gastroenterol Nutr 1996; 23:591-8.

16 Leite LP, Johnston BT, Barrett J, et al. Ineffective esophageal motility (IEM). The primary finding in patients with nonspecific esophageal motility disorder. Dig Dis Sci 1997;42:1859-65.

17 Fouad YM, Katz PO, Hatlebakk JG, et al. Ineffective esophageal motility: the most comon motility abnormality in patients with GERD-associated respiratory symptoms. Am J Gastroenterol 1999:94:1464.

18 Kahrilas PJ, Dodds WJ, Hogan WJ, et al. Esophageal peristaltic dysfunction in peptic esophagitis. Gastroenterology 1986:91:897-904.

19 Basilisco G, Carola F, Vanoli M, et al. Oesophageal acid clearance in patients with systemic sclerosis: effect of body position. Eur J Gastroenterol Hepatol 1996;8:205-9.

20 Conklin JL. Nitric oxide: a mediator of esophageal motor function. J Lab Clin Med 1998;131:10-20.

21 Moreland RB, Goldstein I, Traish A. Sildenafil, a novel inhibitor of phosphodiesterase type 5 in human corpus cavernosum smooth muscle cells. Life Sci 1998:62:309-18.

22 Bortolotti M, Mari C, Lopilato C, et al. Effects of sildenafil on esophageal motility of patients with idiopathic achalasia. Gastroenterology 2000; 118:253-7.

23 Zhang $X$, Tack J, Janssens J, et al. Effect of sildenafil, a phosphodiesterase-5 inhibitor, on oesophageal peristalsis and lowe oesophageal sphincter function in cats. Neurogastroenterol Motil 2001;13:325-31.

24 Rhee PL, Hyun JG, Lee JH, et al. The effect of sildenafil on lowe esophageal sphincter and body motility in normal male adults. Am J Gastroenterol 2001;96:3251-7.

25 Cook DI, Van Lennep EW, Roberts ML, et al. Secretion by the major salivary glands. Johnson LR, ed. Physiology of the Gastrointestinal Tract, 3rd edn. New York: Raven Press, 1994:1061-117.

26 Patel R, Launspach J, Soffer E. Effects of cisapride on salivary production in normal subjects. Dig Dis Sci 1996;41:480-4.

27 Shay SS, Eggli D, Johnson LF. Simultaneous esophageal pH monitoring and scintigraphy during the postprandial period in patients with severe and scintigraphy during the postprandial period in

28 Holloway RH, Tippet $M$, Horowitz $M$, et al. Relationship between esophageal motility and transit in patients with type I diabetes mellitus. Am J Gastroenterol 1999;94:3150-7.

29 Dodds WJ, Kahrilas PJ, Dent J, et al. Analysis of spontaneous gastroesophageal reflux and esophageal acid clearance in patients with reflux esophagitis. J Gastrointest Motil 1990;2:79-89.

30 Timmer R, Breumelhof R, Nadorp JHSM, et al. Oesophageal motor response to reflux is not impaired in reflux esophagitis. Gut 1993;34:317-20.

31 Shay SS, Johnson LF. Upright refluxers without esophagitis differentiated from bipositional refluxers with esophagitis by simultaneous manometry and $\mathrm{pH}$ monitoring conducted in two postures before and after a meal. Am J Gastroenterol 1994:89:992-1002.

32 Barham CP, Gotley DC, Mills A et al. Oesophageal acid clearance in patients with severe reflux oesophagitis. Br J Surg 1995;82:333-7.

33 Shay SS, Richter JE. Importance of additional reflux events during esophageal acid clearing. Dig Dis Sci 1998;43:95-102.

34 Lin S, Ke M, Xu J, et al. Impaired esophageal emptying in reflux disease. Am J Gastroenterol 1994;89:1003-6.

35 Diener U, Patti MG, Molena D, et al. Esophageal dysmotility and gastroesophageal reflux disease. J Gastrointest Surg 200 1;5:260-5. 